\title{
Post Covid-19 Pandemic Driving Gun Violence and Mass Shooting Rise Nationwide (A Short Review)
}

\section{Bahman Zohuri ${ }^{1,2,3 *}$}

${ }^{1}$ Golden Gate University, Ageno School of Business, San Francisco, California, USA

${ }^{2}$ Galaxy Advanced Engineering, A Consulting Firm, Albuquerque, New Mexico, USA

${ }^{3}$ International Technological University, CS and ECE Department Santa Clara,

California, USA

*Corresponding Author: Bahman Zohuri, Adjunct Professor, Artificial Intelligence

and Machine Learning, California, USA.
Received: July 05, 2021

Published: July 23, 2021

(C) All rights are reserved by Bahman Zohuri.

\begin{abstract}
With post covid-19 pandemic and gradual relief from shelter in place order, which is in process of being lifted, we see tremendous rise in mass shooting and gun violence nationwide and cross all the states. Sales of handguns and assault weapon market is in ascending demand. Purchasing bolts now is a rare market commodities and purchase prices has been doubled and tripled in recent months drive by post pandemic event taking place. With new laws in state like Texas that now is allowing their citizen to carry their guns in plane seen and visible without any permit license and background check is a dilemma and adding sault to injury as well. Most police chiefs cross the cities within nation are complaining about sale of ghost guns that are crossing their boundary of their cities, where they have no control over the identity of their owners of these types of guns. In addition, with rise of cryptocurrency and digital currency as trading tool, purchase of ghost guns and assault weapons are becoming much easier consequently as well.
\end{abstract}

Keywords: Post Pandemic; Covid-19; Cryptocurrency; Digital Currency; Gun Violence; Assault Weapons; Homicides

\section{Introduction}

The rate of firearm and gun violence is in rise given post Covid-19 pandemic and release from shelter in place order since March of 2020. The new statistics shows the rate of gun violence has been risen per 100,000 people from $10.3 \%$ in year 1999 to $12.0 \%$ per 100,000 in as recent as year 2017 and continue rising that is now driven by post Covid-19 pandemic. With 109 people dying per day or about 14,542 homicide in total this rate was being 11.9 percent per 100,000 in 2018 , which brings the total to 1.4 million people that have died from guns and assault weapons in the United States between 1968 and 2011. Figure 1 is indication of historical data related to rate of gun violence and assault firearms, thus murdered victim in U.S.

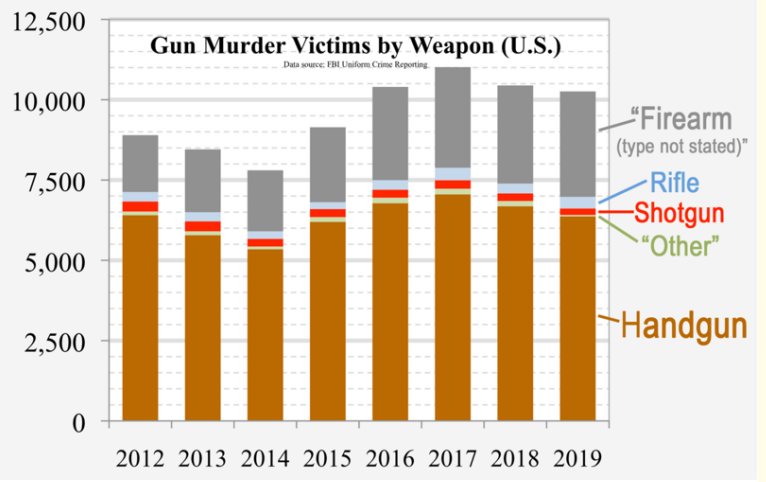

Figure 1: Handguns are Involved in most U.S. Gun Homicides (Source: www.wikipedia.org). 


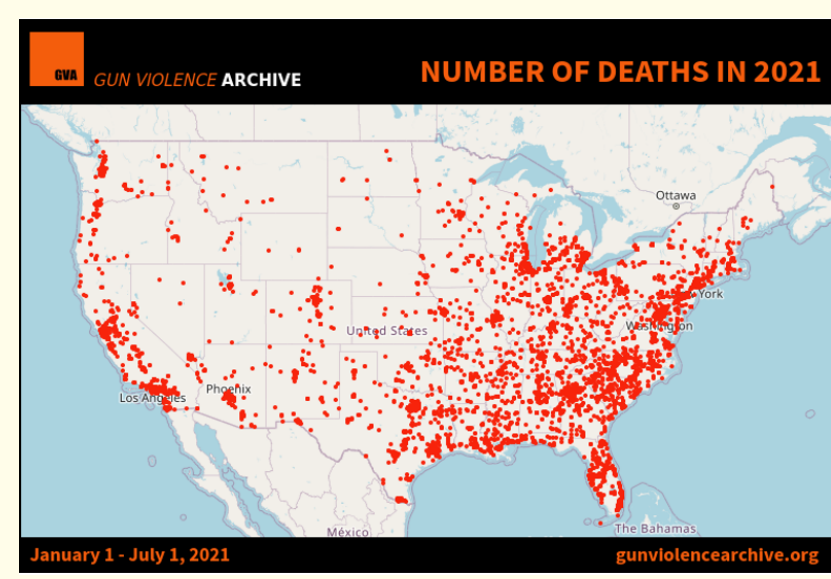

Figure 2: Number of Deaths in 2021

(Source: www.gunviolence.org) [5].

\begin{tabular}{|c|c|c|c|c|c|c|}
\hline GVA - SIX YEAR REVIEW & 2014 & 2015 & 2016 & 2017 & 2018 & 2019 \\
\hline Deaths - Willful, Malicious, Accidental & 12,418 & 13,537 & 15,112 & 15,679 & 14,789 & 15,20 \\
\hline Suicides by Gun & 21,386 & 22,018 & 22,938 & 23,854 & 24,432 & PENDING \\
\hline Injuries - Willful, Malicious, Accidental & 22,779 & 27,033 & 30,666 & 31,265 & 28,233 & 29,501 \\
\hline Children [age 0-11] Killed or Injured & 603 & 695 & 671 & 733 & 670 & 692 \\
\hline Teens [aged 12-17] Killed or Injured & 2,318 & 2,695 & 3,140 & 3,256 & 2869 & 3,068 \\
\hline Mass Shooting & 269 & 335 & 382 & 346 & 337 & 417 \\
\hline Murder-Suicides & 624 & 530 & 549 & 608 & 621 & 614 \\
\hline Defensive Use [DGU] & 1,531 & 1,393 & 2,001 & 2,107 & 1888 & 1,547 \\
\hline Unintentional Shootings & 1,605 & 1,969 & 2,202 & 2,039 & 1662 & 1,837 \\
\hline \multicolumn{7}{|c|}{ 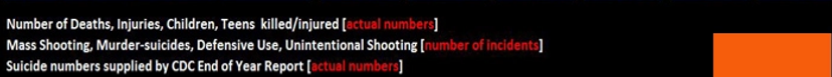 } \\
\hline $\begin{array}{l}\text { Qgundeaths } \\
\text { www.gunviolencearchive.org } \\
\text { www.tacebook.com/gunviolencearchive }\end{array}$ & & & & & & GU/ \\
\hline
\end{tabular}

Figure a: Gun Violence Between 2014 To 2019 (Source: www. gunviolence.org) [5].

According to Amnesty International, the key facts behind gun violence and increase on mass shooting and life threatening, also has tremendous psychological impact on daily life of folks involved in a tragedy gun violence either directly or indirectly for a longterm either mentally or health-wise as well. Recent gang shooting within free-way in southern California, resulted in loos of a 5 year old kid in her mom's car while they were driving to school and they had nothing with this gang shooting except being an innocent folks driving on freeway and minding their own business, yet bully driving others caused murder of this five years old kid. The impact of such memory will stay with mom and father of this kid for a long, long time with no doubt [1].

"Gunshot injuries are often life-changing and have an indelible impact on the victims' long-term mental and physical health. Some need permanent, lifelong care, and many others lose their ability to work, particularly in physically demanding jobs. Yet programs offering adequate long-term care, rehabilitation and job retraining are virtually non-existent. The toll that gun violence has on victims, family members and the medical services has resulted in a chronic public health crisis - with remarkably little government response. Access to affordable and quality health care services in the USA should include necessary long-term health interventions, including long-term pain management, rehabilitation and other support services, and mental health care" [1].

\section{Gun violence driven death and injury statistics}

Historical data shows that more than 500 folks are dying every day via gun shooting and $44 \%$ of all homicides globally is due to the gun violence, where 1.4 million death counts for related gun violence, globally between 2012 and 2016 time period [2].

Statistically, the data obtained from The Centers for Disease Control and Prevention (CDC) bureau for National Center for Health Statistics reports from 2018 up to now, indicates most victims are youngsters who are among low income poverties and people of colors. The report states that 38,390 deaths by firearm of which 24,432 were accounted by suicide $[3,4]$.

Furthermore, statistical data presented by charts and maps gathered by Gun Violence Archive 2021 based on research and evidence since 2013 are presented in figure 3 and figure a, that also illustrates gun violence and crime incidents are collected and validated from 7,5000 source on daily events. Incident reports and their source data are found at the gunviolencearchive.org website [5].

In United States alone, nearly 134,000 people were shot and injured by firearms in 2017. The statistics of firearm deaths and injuries between period 2019 and 2020 depicted in figure 3. 


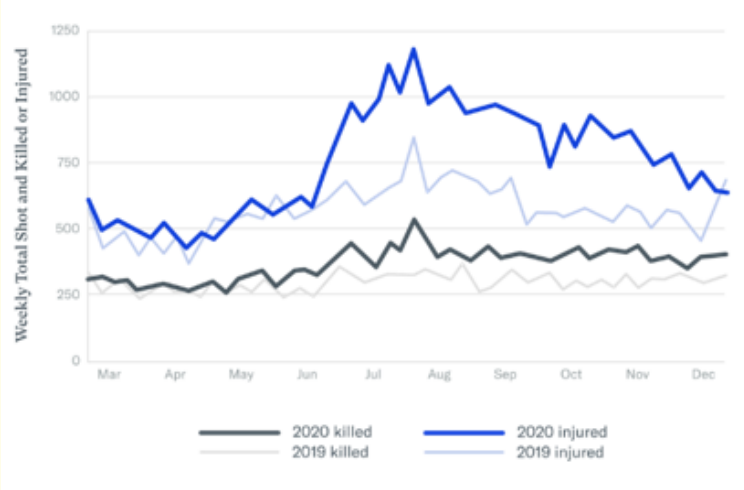

Figure 3: Firearm Deaths and Injuries in 2019 to 2020 in USA [6].

The increase in gun violence and mass shooting driven by post covid-19 pandemic rise is becoming a serious dilemma in United States. Not only gun violence a problem in USA, it is also a worldwide issues among rich countries with high Gross Domestic Product (GDP) as well and figure 4 is illustration such issue.

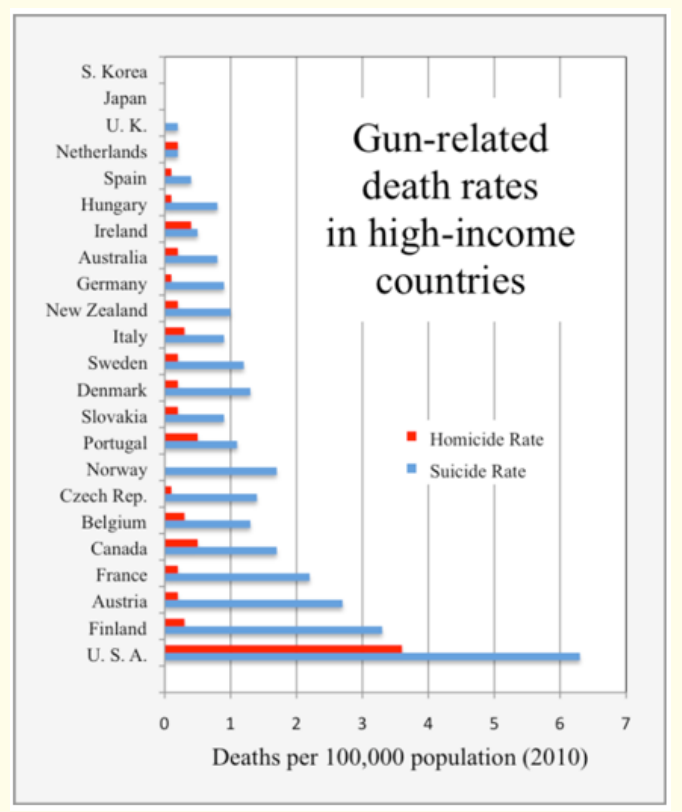

Figure 3: Firearm Deaths and Injuries in 2019 to 2020 in USA [6].
In United States alone, gun ownership is on rise as well and the Congressional Research Service in 2009 estimated there were 310 million firearms in the U.S.A, not including weapon owned by the military. Figure 5 is illustration of Sates with most firearm background checks per 100,000 people in 2019 , which is a good correlation and indication of gun ownership accordingly.

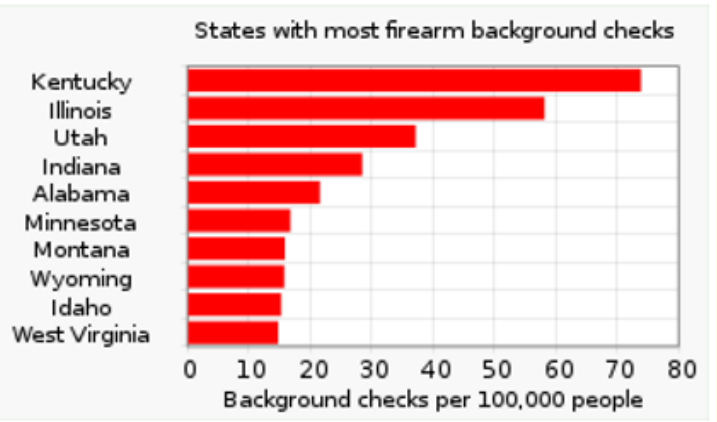

Figure 5: States with Most Firearm Background Checks (Source: www.wikipedia.org).

However, the figure 5 has no data in respect to ghost guns and their owners, where these type of guns do not require any background check, thus does not require to obtain any license to own and carry these type of guns either.

Moreover, figure 6, is illustration of gun owners as a percentage of each U.S. state's population in 2007 as well.

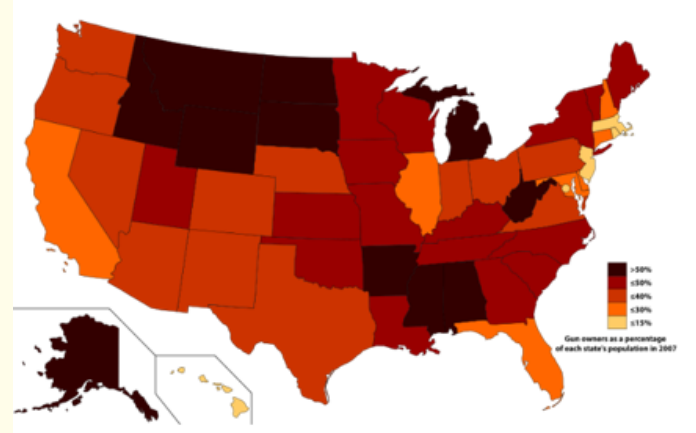

Figure 6: Gun owners as a percentage of each U.S. state's population in 2007 (Source: www.wikipedia.org). 
Law enforcement agencies, reporting increased firearm homicide or nonfatal shootings percent changes since 2019 as illustrated in figure 7.

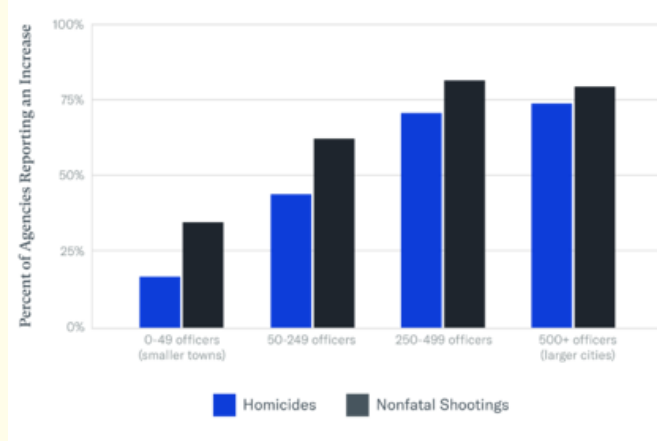

Figure 7: Law Enforcement Agencies Reporting Increased Firearm Homicide or Nonfatal Shootings, Percent Change Since Change Since 2019 [8].

According to everytownresearch.org website, as result of COVID-19 and in particular post COVID-19 pandemic, many cities are facing an increase about the number of people shot and wounded or killed.

"In January 2021, researchers surveyed 129 law enforcement agencies representing a diverse set of cities across the United States in terms of size, demographics, and geographic coverage. They found that in nearly 70 percent of these agencies, nonfatal shootings increased, and in 57 percent, there was an increase in gun homicides from 2019 to 2020.

This survey also found that the largest agencies-that is, those serving the largest cities-were more likely to report an increase in gun homicides and nonfatal shootings: Nearly three in four reported an increase in firearm homicides and four out of five saw increases in nonfatal shootings" [8,9].

\section{COVID-19 pandemic driving gun violence}

Shelter in place order federal and local government was first in place the minute, the Centers for Disease Control and Prevention (CDC) announced the first death in United States of America on 1 March 2020 due to COVID-19 pandemic.
Within a year from that date, CDC announced over 28.7 million confirmed cases of COVID-19 and 515,700 death and meanwhile during same period, the gun violence epidemic has also surged [10].

One of the devasting side effects of COVID-19 pandemic and shelter in place order was taking place has been severe depression and consequently, it in United States alone, has been the collision course between the two major public health crises over the past year, namely COVID-19 and the gun violence rising up with a rapid mode.

"We still don't fully understand how damaging this collision has been, and we don't yet fully know how it will continue to affect Americans. But what we do know is the effects have been far-ranging. For one, the pandemic has had a pronounced impact on gun violence in the United States as both homicides and unintentional shootings increased to record levels in 2020" [8].

Historically, The Centers for Disease Control reports that there were 11,078 gun homicides in the U.S. in 2010 [10]. This is higher than the FBI's count. The CDC also stated there were 14,414 (or 4.4 per 100,000 population) homicides by firearm in 2018 and stated that there was a total of 19,141 homicides (5.8 per 100,000 population) in 2019. Figure 8 and 9 are illustrating, the historical homicide by weapons type and offenders by age between period of 1976 and 2004 [11].

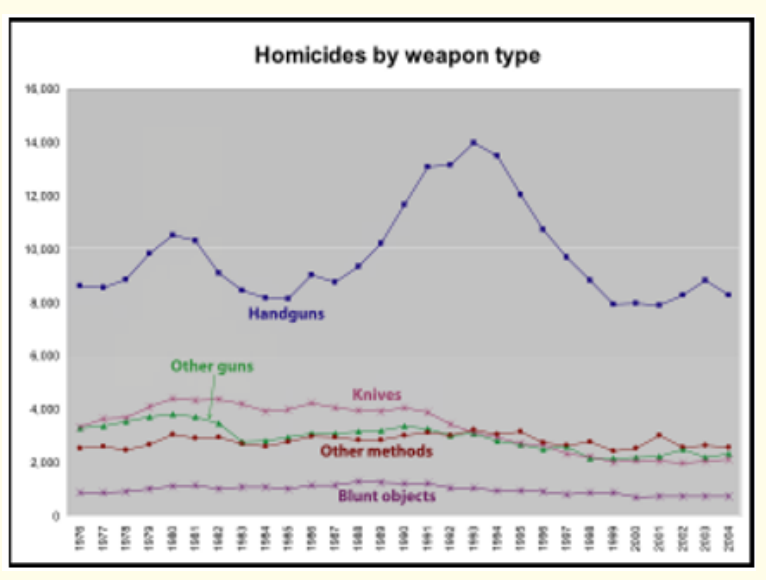

Figure 8: U.S. Homicides by Weapon Type, 1976-2004 [13]. 


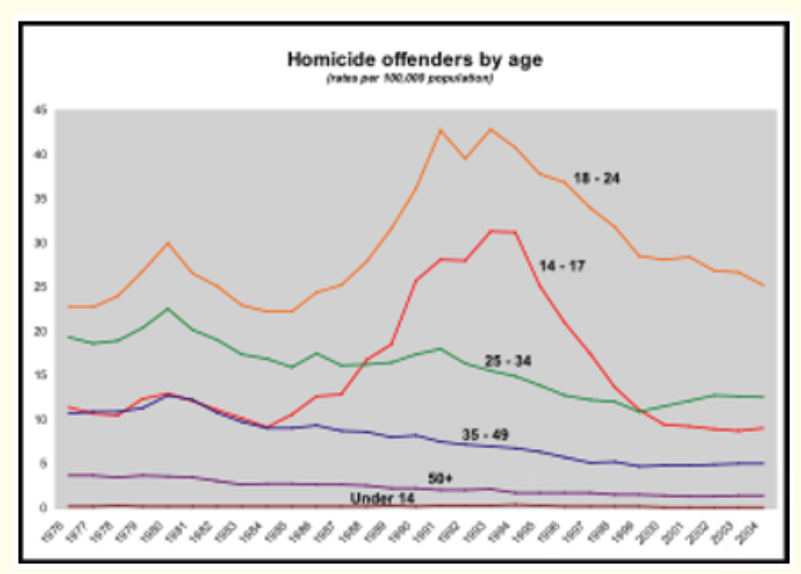

Figure 9: U.S. Homicide Offenders by age, 1976-2004 [14].

Furthermore, figure 10 is illustration of firearm related hospitalizations in United Sates of America between period of 2000 and 2015 that is indication of hospitalizations for injury by different types of gun in hand of people that accounts for an estimated \$2.8 billion in health-care spending annually and billions more in lost work and wages, without even into account devasting moral impact and comes with it the depression aspect of it.

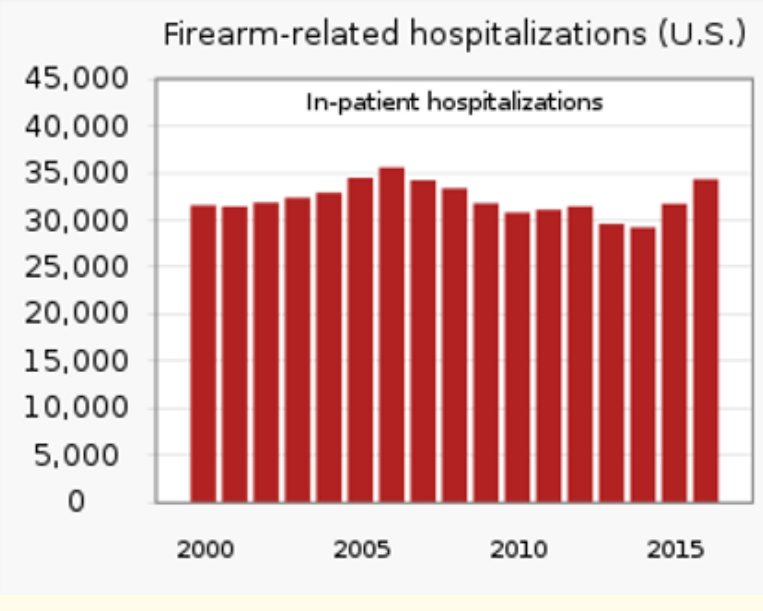

Figure 10: U.S. Firearm-Related Hospitalizations [14].
Surprising, with a 2017 study finding that the average gunshot patient incurred hospital costs of more than $\$ 95,000$ [15].

Though gun-related injury rates are less closely tracked than gun-related death rates, state-by-state gun ownership rates were found not to be closely correlated with gun hospitalizations, but gun-related hospitalizations were found to be closely correlated with rates of violent crime overall and with poverty rates [15].

Consequently, as part of reforming police force program and as part of effort "Black Life Matters" movement cross the nation due to clash between police and civilian in particular African American folks, that is on news in recent days, it is imperative that cities and states sustain funding for gun violence prevention programs as well.

However, even community gun violence intervention program such as paying cash for gun owner alone, cannot mitigate the structural inequity that fuels gun violence and mass shooting post-COVID-19 pandemic, specially.

Lessons learned from this pandemic include the imperative to invest in the broader resource's communities require to be safe and healthy. Long-term interventions include support for communitydriven crime prevention by environmental design (e.g., cleaning vacant lots, greening parks, and providing additional outdoor lighting)19 and summer youth employment programs [16].

Counseling and mentorship services for youth21 and cognitive behavioral therapy are also proven to help reduce violence [17].

\section{COVID-19 and isolation driven depression}

Mental health can affect daily life, relationships, and even physical health. Mental health also includes a person's ability to enjoy life - to attain a balance between life activities and efforts to achieve psychological resilience [20]. One of the side effects of modern technology and our dependency on electronic gadget is isolation and living in a silo mode among the youths and being member of a social media is like adding salt to injury as far as we are concerned (See figure 11). 


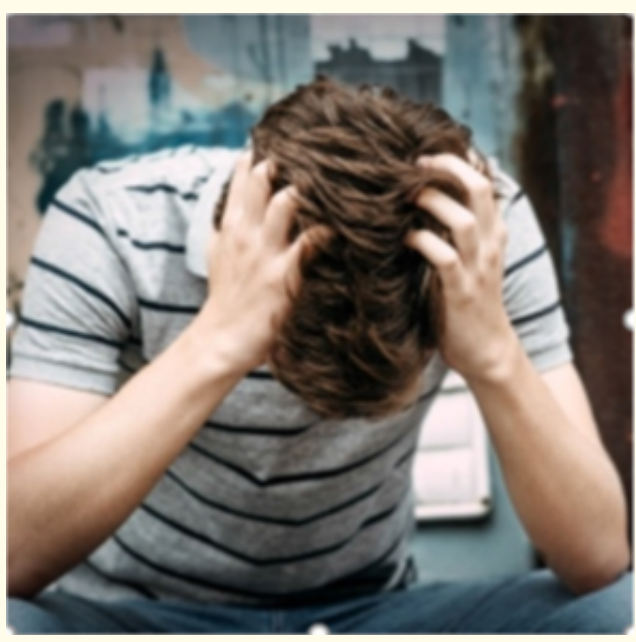

Figure 11: Isolation and Silo Daily Life.

COVID-19 affects and social distancing by virtue shelter in place order is no different than above arguments here that causes some means of depression and consequently, an action like this to isolate people has a reaction such as post-pandemic and increase in gun violations and mass shooting that we are observing daily on the news.

One defining aspect of the COVID-19 crisis has been the closing of America's schools. This kept children home across the country and, in too many cases, put them into direct contact with the millions of guns in American homes. In some households, these were first-time gun owners, who were often unable to access training due to the pandemic-leaving many of them without essential knowledge on how to securely store firearms.

The above argument is a base root for unintentional shooting by children and the risk of youth gun suicide as well.

Before the pandemic, on average nearly one child per day was accessing a gun and unintentionally shooting themselves or another person [21].

With children stuck at home, we clearly see the consequences of guns not being stored properly. The period from March to December 2020 saw a 31 percent increase over the same months in 2019 in unintentional shooting deaths by children.
In total, there were 314 incidents of unintentional shootings by children between March and December of 2020, resulting in 128 gun deaths and 199 nonfatal gun injuries [22].

"This includes toddlers, young children, and teenagers 17 and younger accessing a gun and unintentionally injuring or fatally wounding a sibling, a schoolmate, another family member or friend, or themselves" [6].

Surging gun sales and firearm market

There were an estimated 22 million guns purchased in 2020, which was a surge of $64 \%$ increase over 2019 according to the law enforcement authorities both at Federal and Local levels as illustrated in figure 12.

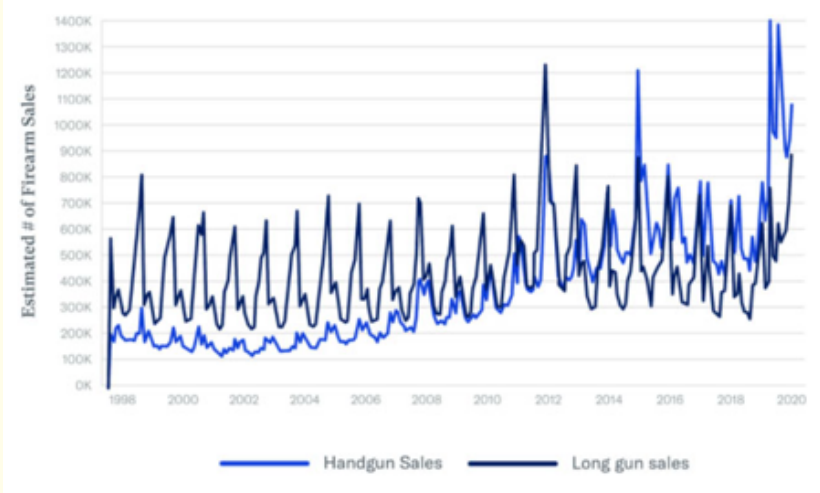

Figure 12: Gun Purchase Trend [6].

This surge in gun sales has continued into 2021 and in January 2021, it was reaching almost to 2.1 million guns were sold. However, this number is based on year 2020 (Figure 11) and federally licensed gun dealer's data, which was requested for nearly 40 million background checks, and it does not take into account ghost gun sales at flea market places across the nation and therefore, is accounted for $40 \%$ more than during 2019.

The above estimation is also coming from National Instant Criminal Background Checks System (NICS) organization since the system became operational in 1998.

According to Everytown report [6], it seems that the reasoning behind such rise in firearm purchase and ownership is behind 
social distancing and shelter in place order due to COVID-19 pandemic.

The US government declared a national emergency and states released social distancing guidelines in mid-March 2020. Almost immediately after, many Americans purchased guns; they felt they had to protect themselves, partially in response to gun lobby propaganda that social unrest was inevitable, and that the government would not protect them [18].

National Rifle Association and gun rights advocates off course, arguing that policy aimed at the supply side of the firearm market is based on limited research and this is based on one consideration that $60-70 \%$ of firearm supply and consequently sales in the U.S. are transacted through federally licensed firearm dealers, with rest coming from the "secondary market", in which previously owned firearms are transferred by non-dealers and yet, and not taking ghost gun sale into account at all.

However secondary market for purchase of a gun is inconvenient and risky to purchase and involves taking a chance of the possibility of the gun having been used previously in a crime or homicide and as depicted in figure 13 is a good indication of such owners of this type of guns or assault weapons that should be in hand of military and law enforcement not regular folks that are arguing their ownership under "First Amendment" and thus, selfdefense.

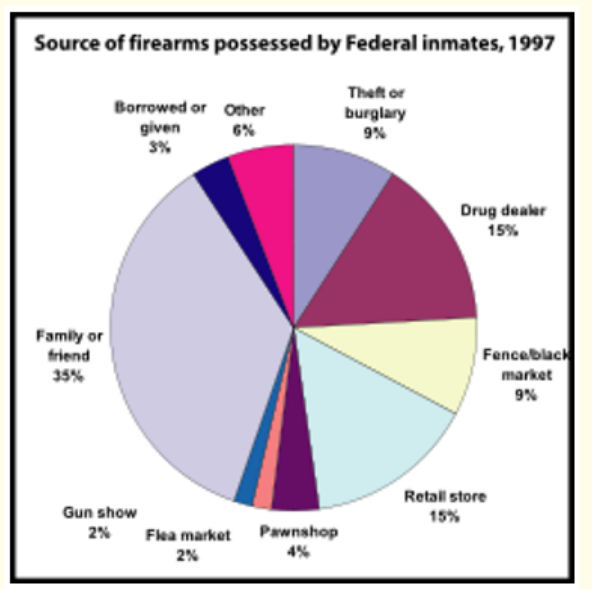

Figure 13: Source of firearms possessed by Federal inmates, 1997 [19].
Criminals tend to obtain guns through multiple illegal pathways, including large-scale gun traffickers, who tend to provide criminals with relatively few guns [19]. Federally licensed firearm dealers in the primary (new and used gun) market are regulated by the Bureau of Alcohol, Tobacco, Firearms, and Explosives (ATF). Firearm manufacturers are required to mark all firearms manufactured with serial numbers. This allows the ATF to trace guns involved in crimes back to their last Federal Firearms License (FFL) reported change of ownership transaction, although not past the first private sale involving any particular gun.

\section{Conclusion}

The increase in gun violation and mass shooting, during pandemic and post pandemic is an eye opener events for us.

This COVID-19 pandemic was an eye opener for us by shining a light on us as a nation, but also suggests an illumination for the path forward. With more guns in hand of people, we are more exposed to a higher risks of suicide and more homicides and unintentional shooting as well [23].

As part of our reform and rectification of our work must include implementing proven policies that protect ourselves and others around us. We must be more rigorous background check system and promote secure gun storage as well stopping ghost gun and secondary market is concerned.

It is imperative that we fund community-based violence intervention and suicide prevention programs. And that we adopt and implement Extreme Risk laws and policies separating domestic abusers from their guns, both of which are proven to save lives.

Some local jurisdictions in the U.S. have more restrictive laws, such as Washington, D.C.'s Firearms Control Regulations Act of 1975, which banned residents from owning handguns, and required permitted firearms be disassembled and locked with a trigger lock.

Some propose keeping a gun at home to keep one safer. Studies show that guns in the home is associated with an increased risk of violent death in the home.

Anyway, going forward into a future path, we have to make harder for folks to own a gun or assault weapons and look into their background with tooth of comb. 


\section{Bibliography}

1. Gun violence - key facts | Amnesty International (2021).

2. Claire McEvoy and Gergely Hideg SAS-Report-GVD (2017).

3. "10 Leading Causes of Injury Deaths by Age Group Highlighting Violence-Related Injury Deaths, United States - 2018". Injury Prevention and Control, CDC.

4. Firearm Injury and Death in the United States (PDF). Violence Prevention Research Program, University of California Davis (2020).

5. Gun Violence Archive.

6. Gun Violence and COVID-19 in 2020: A Year of Colliding Crises | Everytown Research and Policy | Everytown Research and Policy (2021).

7. Data through 2016: "Guns/Firearm-related deaths". NSC.org copy of U.S. Government (CDC) data. Centers for Disease Control and Prevention (2018).

8. https://everytownresearch.org/report/gun-violence-andcovid-19-in-2020-a-year-of-colliding-crises/

9. Police Executive Research Forum. "Daily Critical Issues Reports: Survey on 2020 Gun Crime and Firearm Recoveries". January 26, (2021).

10. “10 Leading Causes of Injury Death by Age Group Highlighting Violence-Related Injury Deaths, United States". National Vital Statistics System. National Center for Health Statistics, CDC (2010).

11. "FBI - Expanded Homicide Data Table 8". Fbi.gov. July 25 (2011).

12. "Homicide trends in the U.S. - Weapons used". Bureau of Justice Statistics. Archived from the original on January 23, 2013 (2011).

13. "Homicide trends in the U.S. - Age trends". Bureau of Justice Statistics (2006).

14. Smart Rosanna., et al. "Inpatient Hospitalizations for Firearm Injury”. Rand.org. Rand Corporation (2021).

15. Ingraham Christopher. "Home Share 142 Business Gun injuries put over a half-million people in hospitals from 2000 to 2016, study finds First-of-its-kind database provides statelevel estimates of gun hospitalizations over time". The Washington Post (2021).
16. Alicia Sasser Modestino. "How Do Summer Youth Employment Programs Improve Criminal Justice Outcomes, and for Whom?". Journal of Policy Analysis and Management 38.3 (2019): 600-628.

17. Sara B Heller., et al. "Thinking, Fast and Slow? Some Field Experiments to Reduce Crime and Dropout in Chicago". Working Paper Series (National Bureau of Economic Research, May (2015).

18. Harry Eberts and Miranda Viscoli. "Gun Lobby, NRA Use Crisis to Boost Gun Sales". Santa Fe New Mexican, April 13, 2020, https://bit.ly/2Tsl7hb; "Americans are flocking to gun stores because they know the only reliable self-defense during a crisis is the \#2A. Carletta Whiting, who's disabled and vulnerable to \#coronavirus, asks Dems trying to exploit the pandemic: Why do you want to leave people like me defenseless?" NRA, “Twitter Post, 1:36 PM" March 21, (2020).

19. Federal Firearm Offenders, 1992-98. Bureau of Justice Statistics.

20. Christian Nordqvist, https://www.medicalnewstoday.com/ articles/154543.php, UK.

21. Everytown for Gun Safety Support Fund. "\#NotAnAccident Index" (2020).

22. Everytown analysis using \#NotAnAccident Index 2019-2020 data. Everytown for Gun Safety Support Fund, "\#NotAnAccident Index".

23. Anglemyer Horvath and Rutherford. "Accessibility of Firearms and Risk". Campbell., et al. "Risk Factors for Femicide". Everytown for Gun Safety Support Fund. "\#NotAnAccident Index".

\section{Volume 5 Issue 8 August 2021}

(C) All rights are reserved by Bahman Zohuri. 